\title{
Real-time implementation of a novel hybrid fuzzy sliding mode control of a BLDC motor
}

Ali Mousmi, Ahmed Abbou, Yassine El Houm

Mohamed V University, Mohammadia School's of Engineers, Morocco

\begin{tabular}{l}
\hline \hline Article Info \\
\hline Article history: \\
Received Nov 21, 2018 \\
Revised Mar 1, 2019 \\
Accepted Mar 19, 2019 \\
\hline Keywords: \\
Brushless DC motor (BLDC) \\
Fuzzy logic control (FLC) \\
Hybrid controller \\
Sliding mode control (SMC) \\
Speed control
\end{tabular}

\section{Corresponding Author:}

Ali Mousmi, Departement of Electrical Engineering, Mohamed V University, Mohammadia School's of Engineers, Ibn Sina, B, P 765 Agdal Rabat, Morocco. Email: amousmi@gmail.com

\begin{abstract}
This paper presents a novel hybrid control of a BLDC motor using a mixed sliding mode and fuzzy logic controller. The objective is to build a fast and robust controller which overcome classical controllers' inconveniences and exploit the fast response of brushless dc motors characterized by an intense torque and fast response time. First the paper study pros and cons of both sliding mode and fuzzy logic controllers. Then the novel controller and its stability demonstration are presented. Finally the proposed controller method is used for the speed control of a BLDC motor $3 \mathrm{KW}$. The obtained results are compared with those of a fuzzy logic and a conventional sliding mode controller. It allows to show performance of the proposed controller in terms of speed response and reaction against disturbances, which is improved more than 5 times without losing stability or altering tracking accuracy.
\end{abstract}

Copyright (c) 2019 Institute of Advanced Engineering and Science. All rights reserved.

\section{INTRODUCTION}

BLDCmotors, also known as permanent-magnet DC synchronous motors have a series of advantages like the simple structure, faster torque response, high efficiency, higher speed ranges, noiseless operation and longer life time. Combining all these benefits makes BLDC motors be more suitable option for industry, such as electric vehicles, robotics, and home appliances [1,2]. Compared to induction machines, the speed and intensity of the electric torque is an undeniable advantage of brushless motors. To benefit from that, taking into account its non-linear nature and modeling errors, one has to build a controller as fast as possible overcoming the problems of parametric uncertainties.

Several control laws have been used for speed control of electric motors including BLDCM, PID controller [3, 4], sliding mode controllers (SMC) [5, 6], Fuzzy logic controllers (FLC) [7, 8] and adaptative control [9] etc.But given the limitations of each controller, researchers are constantly exploring all modern techniques and its different possible combinations in order to setup a non-linear, efficient and robust speed controller which overcomes the disadvantages of conventionalproportional, derivative and integral regulators. For example, PI controller, the most popular in industry, requires a linearized system model and it is very limited in terms of adaptation to load variations and parametric uncertainties.

Sliding mode control is a variable structure control that has grown considerably in recent decades [10-12]. This is mainly due to its simple structure, the fast convergence property in finite time, andits great robustness against modeling errors and some types of external disturbances [12]. The principle of sliding mode control is to constrain the system statetrajectory to reach a given surface, called a sliding surface or sliding variable, and then remain there. The major disadvantage of this control is its discontinuous nature, in practice it induces high frequency switching known as chattering phenomenon once the sliding surface is reached. In fact, these commutations can excite unwanted dynamics which may destabilize, deteriorate or 
even destroy the studied system. There are various methods to reduce this phenomenon, the best known of which is the equivalent control [13] with replacement of the discontinuous function by a continuous approximation in vicinity of the sliding surface (saturation function or sigmoid function). Another method is to use high order sliding modes [14-16], whose principle is to reject the discontinuities bycontrolling and canceling also the upper derivatives of the sliding variable. On the other hand, several ways of optimizing the SMC discontinuous membrane gain using intelligent algorithms were used, e.g, by combining SMC with fuzzy logic [17-19] or with Particle Swarm [20],etc. The general principle of this kind of regulator is to reduce the gain as we approaches the sliding surface and to pass the baton to the so-called equivalent control part to control the system once the sliding surface is reached.It decreases the chattering phenomenon, but in detriment of accuracy, because the discontinuous membrane ensuring performance against parametric uncertainties is weakened.

Fuzzy Logic control is one of the most popular strategies for managing uncertain control systems, based on the fuzzy set theory introduced by ZADIH in 1965 [21]; It is another approach that works without knowingthesystem model, wherethe command is calculated based on heuristic knowledge without knowing the system parameters. It has been successfully applied for different industrial processes control [13], the results show that the fuzzy controller, despite itslittle long response time, gives a perfect pursuit without anyovershoot.

This paper presents a hybrid controller combining performances of two command types; it favorize the sliding mode controller at the dynamic regime and the fuzzy logic controller at static regime, by using a selection function allowing a very smooth commutation between the two controllers. The paper is organized as follows: in the second section the brushless motor model and its operating principle are presented. The third section presents the theory of classical sliding mode, determination of brushless motor control law using this command type and discussion on his problems. In the fourth section, the fuzzy PI controller and its implementation are presented. The fifth section presents the proposed controller and its stability study. The last section will present and discuss the experimental results using a BLDC motor $3 \mathrm{KW}, 80 \mathrm{~V}, 3000 \mathrm{rpm}$.

\section{MODELING OF BRUSHLESS DC MOTOR}

The equivalent model of the BLDCM drive system with theassumption of three-phase symmetric stator windings is shownin Figure 1.

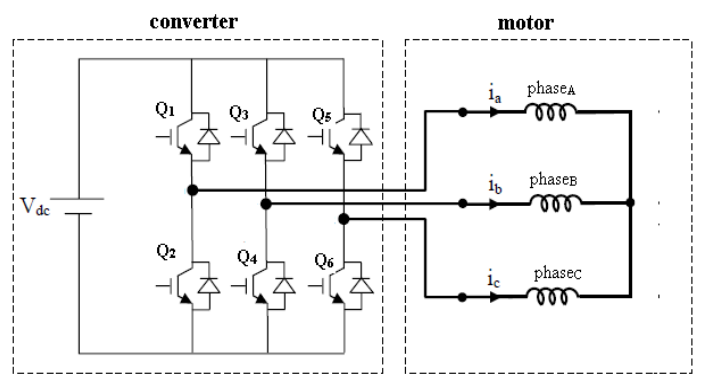

Figure 1. The full bridge driving circuit of BLDC motor

The terminal voltage equation of three-phase stator windingsis expressed as:

$$
\begin{aligned}
& \left\{\begin{array}{l}
\mathrm{V}_{\mathrm{a}}=\mathrm{Ri}_{\mathrm{a}}+\mathrm{L} \frac{\mathrm{di}_{\mathrm{a}}}{\mathrm{dt}}+\mathrm{e}_{\mathrm{a}} \\
\mathrm{V}_{\mathrm{b}}=\mathrm{Ri}_{\mathrm{b}}+\mathrm{L} \frac{\mathrm{di}_{\mathrm{b}}}{\mathrm{dt}}+\mathrm{e}_{\mathrm{b}} \\
\mathrm{V}_{\mathrm{c}}=\mathrm{Ri}_{\mathrm{c}}+\mathrm{L} \frac{\mathrm{di} \mathrm{c}_{\mathrm{c}}}{\mathrm{dt}}+\mathrm{e}_{\mathrm{c}}
\end{array}\right. \\
& \mathrm{T}_{\mathrm{em}}=\frac{\mathrm{e}_{\mathrm{a}} \mathrm{i}_{\mathrm{a}}+\mathrm{e}_{\mathrm{b}} \mathrm{e}_{\mathrm{b}}+\mathrm{e}_{\mathrm{c}} \mathrm{i}_{\mathrm{c}}}{\Omega}
\end{aligned}
$$


Where $R$ is the stator resistance, $\mathrm{L}$ is the stator inductance, $\mathrm{V}_{\mathrm{a}}, \mathrm{V}_{\mathrm{b}}$ and $\mathrm{V}_{\mathrm{c}}$ are the terminal voltages of the three-phase stator winding respectively; $i_{a}, i_{b}$ and $i_{c}$ are the stator currents; $e_{a}, e_{b}$ and $e_{c}$ are the phase back EMFs; $T_{\mathrm{em}}$ and $\Omega$ represent electromagnetic torque and rotor angular velocity respectively.

The controlled brushless DC motor consists of a three phase windings stator and a permanent magnet rotor Figure 1 and its windings are star connected. The motor is operated in two phases conduction mode in which each phase voltage is energizedfor an interval of $120^{\circ}$ electrical according to the rotorelectrical position. Basically, there are six different sectors, in which just two phases are powered; one is connected to the positive terminal of the $\mathrm{DC}$ bus $+\mathrm{V}_{\mathrm{DC}}$ and the other to $-\mathrm{V}_{\mathrm{DC}}$. The rotor position is determined using three Hall Effect sensors installed in the stator with a shift of $120^{\circ}$ electrical. Table 1 gives the different possibilities to supply the motor according to the rotor position.

Table 1. Truth table of Hall Effect sensors and gate state

\begin{tabular}{cccccccc} 
& \multicolumn{3}{c}{ Hall Sensors } & Active & \multicolumn{3}{c}{ Phases currents } \\
Seq & C & B & A & switches & C & B & A \\
\hline 1 & 1 & 0 & 1 & Q1-Q4 & OFF & DC- & DC+ \\
2 & 1 & 0 & 0 & Q5-Q4 & DC+ & DC- & OFF \\
3 & 1 & 1 & 0 & Q5-Q2 & DC+ & OFF & DC- \\
4 & 0 & 1 & 0 & Q3-Q2 & OFF & DC+ & DC- \\
5 & 0 & 1 & 1 & Q3-Q6 & DC- & DC+ & OFF \\
6 & 0 & 0 & 1 & Q1-Q6 & DC- & OFF & DC+ \\
\hline
\end{tabular}

\section{BLDC MOTOR CONTROL SCHEME}

3.1. Simplification of the model

The brushless motor can be modeled as Figure 2 and Figure 3:

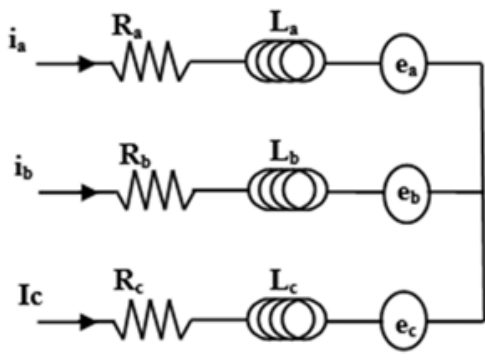

Figure 2. The BLDC motor circuit

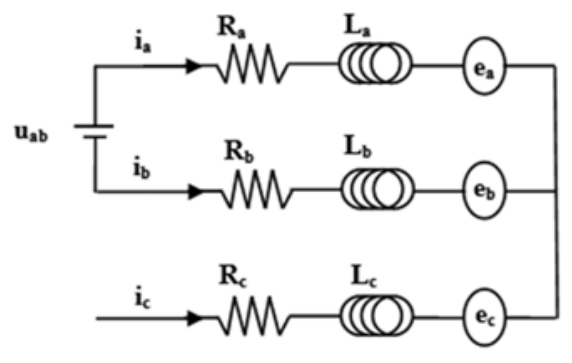

Figure 3. The BLDC motor circuit in sequence 1

Consider the first sequence characterized by:

$$
\left\{\begin{array}{l}
\mathrm{i}_{\mathrm{a}}=-\mathrm{i}_{\mathrm{b}}=\mathrm{I}, \mathrm{i}_{\mathrm{c}}=0 \text { with } \mathrm{U}_{\mathrm{ab}}>0 \\
\mathrm{e}_{\mathrm{a}}=-\mathrm{e}_{\mathrm{b}}=\mathrm{K}_{\mathrm{e}} \Omega=\mathrm{E}_{\mathrm{m}}
\end{array}\right.
$$

The three phases of the motor are symmetrical $\left(\mathrm{R}_{\mathrm{a}}=\mathrm{R}_{\mathrm{b}}\right.$ and $\left.\mathrm{L}_{\mathrm{a}}=\mathrm{L}_{\mathrm{b}}\right)$. So:

$$
\mathrm{U}_{\mathrm{ab}}=\mathrm{V}_{\mathrm{a}}-\mathrm{V}_{\mathrm{b}}=2 \mathrm{R}_{\mathrm{a}} \mathrm{I}+2\left(\mathrm{~L}_{\mathrm{a}}-\mathrm{M}\right) \frac{\mathrm{dI}}{\mathrm{dt}}+2 \mathrm{E}_{\mathrm{a}}
$$

Where $\mathrm{M}$ is the mutual stator inductance.

And by posing

$$
R=2 R_{a}, L=2\left(L_{a}-M\right) \text { and } E=2 E_{m}
$$

We obtain an expression which is the same as the electrical equation of the DC machine: 


$$
\mathrm{U}_{\mathrm{ab}}=\mathrm{RI}+\mathrm{L} \frac{\mathrm{dI}}{\mathrm{dt}}+\mathrm{E}
$$

In the same way, studying the other zones, lead us to the electrical equation of a DC motor.

The control of the self-driven BLDC motor is therefore similar to a separately excited DC motor where the speed is directly proportional to the voltage applied to the motor terminals.And to change this voltage, in this paper, we attack the arms of the inverter by a PWM signal of which we vary the duty cycle to obtain the desired voltage and the desired speed accordingly.

\subsection{First order sliding mode}

Sliding mode is a type of variable structure controls.It consists on defining a stable dynamic relationship between the system state variables called sliding surface then force its trajectory to converge to this surface and stay there. The evolution of the system, submitted to a control law that makes it stay on the given surface, therefore no longer depends on the system itself or disturbances of which it may be submitted, but only depends on the properties of this surface.

The first-order sliding mode control takes the following form:

$$
\mathrm{u}=\mathrm{u}_{\mathrm{disc}}=\mathrm{K} \operatorname{sign}(\mathrm{S})
$$

Considering a nonlinear system in the canonical form of Brunovsky [10]:

$$
\begin{aligned}
& \left\{\begin{aligned}
\dot{x}_{1} & =x_{2} \\
\vdots & \\
\dot{x}_{n} & =f(x, t)+b(x, t) u
\end{aligned}\right. \\
& {\left[x_{1} \ldots x_{n}\right] \in \mathfrak{R}^{n} \text { is the system state vector and } x_{1}=y}
\end{aligned}
$$

A necessary condition for the establishment of a sliding regime is that the sliding variable has a relative degree equal to 1 compared to the control $u$ [9].

So consider the following linear sliding variable [10]:

$$
\mathrm{S}(\mathrm{e}, \mathrm{t})=\sum_{0}^{\mathrm{n}-1} \mathrm{c}_{\mathrm{i}} \mathrm{e}^{(\mathrm{i})}
$$

Whwew e $=\mathrm{y}-\mathrm{y}_{\text {ref }}$ and $\mathrm{c}_{\mathrm{n}-1}=1$

The coefficients ciare chosen such that the polynomial (10) is a polynomial of Hurwitz.

$$
\alpha^{\mathrm{n}-1}+\mathrm{c}_{\mathrm{n}-2} \alpha^{\mathrm{n}-2}+\ldots \ldots+\mathrm{c}_{1} \alpha=0
$$

IfS(e,t)satisfies the condition on the relative degree, the control $u$ appears in the expression of its first time derivative, and :

$$
\dot{S}(e, t)=f(x, t)+b(x, t) u+\sum_{0}^{n-2} c_{i} e^{(i+1)}
$$

Many studies were performed in order to reduce or eliminate the chattering, One of them consists in replacing the sign function by a smooth function in vicinity of the sliding surface, for example saturation function, sigmoid functionsetc; thus the sliding regime resulting is confined in a neighborhood of the sliding surface where only the equivalent command acts [7]. The command takes the following form:

$$
\mathrm{u}=\mathrm{u}_{\mathrm{disc}}+\mathrm{u}_{\mathrm{disc}}
$$

Where $\mathrm{u}_{\mathrm{eq}}$ and $\mathrm{u}_{\mathrm{disc}}$ represent respectively equivalent and discontinuous commands.

Int J Pow Elec \& Dri Syst, Vol. 10, No. 3, Sep 2019 : 1167 - 1177 
The equivalent command can be defined as the average value of the discontinuous control [7]. Its expression is found by annulling the sliding surfacederivative. The idea of this command is that far from the sliding surface the discontinuous portion is responsible for converging the state trajectory to the surface, but when the trajectory is sufficiently near from it (reaching the vicinity prefixed $\varepsilon$ ), the discontinuous control begins to diminish and vanish completely when the surface value becomes zero; so that, quivalent command acts alone and makes invariant the sliding surface. So, to eliminate the control discontinuous membrane and the chatteringphenomenon therefore, we replace the function sign ( $\mathrm{S}$ ) by another continuous function at $\mathrm{S}=0$, likefunction sat $(\mathrm{S})$.

Applying the command with form in (12), we have:

$$
\dot{\mathrm{S}}(\mathrm{e}, \mathrm{t})=\mathrm{f}(\mathrm{x}, \mathrm{t})+\mathrm{b}(\mathrm{x}, \mathrm{t}) \mathrm{u}_{\text {eq }}+\mathrm{b}(\mathrm{x}, \mathrm{t}) \mathrm{u}_{\text {disc }}+\sum_{0}^{\mathrm{n}-2} \mathrm{c}_{\mathrm{i}} \mathrm{e}^{(\mathrm{i}+1)}
$$

The equivalent command has as a goal to make invariant the sliding surface when the sliding mod is established, generally seeks to make null the sliding surface derivativeif it is applied alone. Its expression is:

$$
\mathrm{u}_{e q}=\mathrm{b}^{-1}(\mathrm{x}, \mathrm{t})\left(-f(x, t)-\sum_{0}^{\mathrm{n}-2} \mathrm{c}_{\mathrm{i}} \mathrm{e}^{(\mathrm{i}+1)}\right)
$$

What makes the evolution of sliding surface function only depending on $\mathrm{u}_{\text {disc }}$ :

$$
\dot{\mathrm{S}}(\mathrm{e}, \mathrm{t})=\mathrm{b}(\mathrm{x}, \mathrm{t}) \mathrm{u}_{\mathrm{disc}}
$$

\subsection{Determination of the control law for the motor BLDC}

Considering the first sequence, where: $i_{a}=I, i_{b}=-I, i_{c}=0, e_{a}=-e_{b}=\mathrm{E}_{m}$ :

From equation (2) the electromagnetic torque expression becomes :

$$
\mathrm{T}_{\mathrm{em}}=\frac{2 . \mathrm{e} . \mathrm{I}}{\Omega}
$$

We have $\mathrm{E}_{\mathrm{m}}=\mathrm{K}_{\mathrm{e}} \Omega$, so :

$$
\mathrm{T}_{\mathrm{em}}=2 \mathrm{~K}_{\mathrm{e}} \cdot \mathrm{I}=\mathrm{K}_{\mathrm{t}} \cdot \mathrm{I}
$$

Replacing in the system mechanical equation (17):

$$
\mathrm{T}_{\mathrm{em}}=\mathrm{J} \frac{\mathrm{d} \Omega}{\mathrm{dt}}+\mathrm{B} \Omega+\mathrm{T}_{\mathrm{L}}
$$

We find :

$$
\mathrm{I}=\frac{\mathrm{J}}{\mathrm{K}_{\mathrm{t}}} \frac{\mathrm{d} \Omega}{\mathrm{dt}}+\frac{\mathrm{B}}{\mathrm{K}_{\mathrm{t}}} \Omega+\frac{\mathrm{T}_{\mathrm{L}}}{\mathrm{K}_{\mathrm{t}}}
$$

Which gives :

$$
\frac{\mathrm{dI}}{\mathrm{dt}}=\frac{\mathrm{J}}{\mathrm{K}_{\mathrm{t}}} \frac{\mathrm{d}^{2} \Omega}{\mathrm{dt}^{2}}+\frac{\mathrm{B}}{\mathrm{K}_{\mathrm{t}}} \frac{\mathrm{d} \Omega}{\mathrm{dt}}
$$

Replacing (19) in (6) :

$$
\frac{\mathrm{d}^{2} \Omega}{\mathrm{dt}^{2}}=\frac{\mathrm{U}_{\mathrm{ab}}}{\mathrm{C}_{1}}-\frac{\mathrm{C}_{2}}{\mathrm{C}_{1}} \frac{\mathrm{d} \Omega}{\mathrm{dt}}-\frac{\mathrm{C}_{3}}{\mathrm{C}_{1}} \Omega-\frac{\mathrm{C}_{4}}{\mathrm{C}_{1}}
$$

With : 


$$
\mathrm{C}_{1}=\frac{\mathrm{LJ}}{\mathrm{K}_{\mathrm{t}}}, \mathrm{C}_{2}=\frac{\mathrm{RJ}+\mathrm{LB}}{\mathrm{K}_{\mathrm{t}}}, \mathrm{C}_{3}=\frac{\mathrm{RB}}{\mathrm{K}_{\mathrm{t}}}+\mathrm{K}_{\mathrm{t}} \text { and } \mathrm{C}_{3}=\frac{\mathrm{RT}_{\mathrm{L}}}{\mathrm{K}_{\mathrm{t}}}
$$

The sliding surface is chosen as:

$$
\mathrm{S}=\frac{\mathrm{de}}{\mathrm{dt}}+\mathrm{K}_{1} \mathrm{e}
$$

$\mathrm{e}=\omega_{\mathrm{r}}-\omega$ is the error in speed.

The sliding surfacederivative is:

$$
\begin{aligned}
& \frac{\mathrm{d} S}{\mathrm{dt}}=\frac{\mathrm{d}^{2} \mathrm{e}}{\mathrm{dt}^{2}}+\mathrm{K}_{1} \frac{\mathrm{de}}{\mathrm{dt}} \\
& \frac{\mathrm{d} \mathrm{S}}{\mathrm{dt}}=\mathrm{g}\left(\Omega, \frac{\mathrm{d} \Omega}{\mathrm{dt}}\right)-\frac{\mathrm{U}}{\mathrm{C}_{1}}
\end{aligned}
$$

With:

$$
\mathrm{g}\left(\Omega, \frac{\mathrm{d} \Omega}{\mathrm{dt}}\right)=\frac{\mathrm{d}^{2} \Omega_{\mathrm{r}}}{\mathrm{dt}^{2}}+\mathrm{K}_{1} \frac{\mathrm{d} \Omega_{\mathrm{r}}}{\mathrm{dt}}+\left(\frac{\mathrm{C}_{2}}{\mathrm{C}_{1}}-\mathrm{K}_{1}\right) \frac{\mathrm{d} \Omega}{\mathrm{dt}}+\frac{\mathrm{C}_{3}}{\mathrm{C}_{1}} \Omega+\frac{\mathrm{C}_{4}}{\mathrm{C}_{1}}
$$

\section{Lyapunov theorem:}

There is a continuously differentiable function, positive definite $V:(x, t) \mapsto V(x, t)$ such that time derivative of $\mathrm{V}$ is semi-definite negative if, and only if 0 is a stable equilibrium point. For the state trajectory to converge towards the sliding surface: Choosing the next Lyapunov function:

$$
\mathrm{V}=\frac{1}{2} \mathrm{~S}^{2}
$$

So that, the surface $S=0$ is attractive over the entire operating range, it suffices that the derivative with respect to time of $\mathrm{V}$ is negative:

$$
\mathrm{S} . \dot{\mathrm{S}}<0
$$

To solve the chattering phenomenon due to the discontinuous nature of the command, the most common way is to replace the sign function with another continuous function, for example the sat function and the addition of so-called equivalent command which controls the system at $\mathrm{S}=0$.

So :

$$
\mathrm{u}=\mathrm{K} \cdot \operatorname{sat}(\mathrm{S})+\mathrm{u}_{\mathrm{eq}}
$$

With: $\mathrm{K}>0$ and $\mathrm{u}_{\mathrm{eq}}$ is the equivalent command calculated by canceling the sliding surface derivative.

$$
\mathrm{u}_{\mathrm{eq}}=\mathrm{C}_{1} \frac{\mathrm{d}^{2} \Omega_{\mathrm{r}}}{\mathrm{dt}^{2}}+\mathrm{K}_{1} \mathrm{C}_{1} \frac{\mathrm{d} \Omega_{\mathrm{r}}}{\mathrm{dt}}+\left(\mathrm{C}_{2}-\mathrm{C}_{1} \mathrm{~K}_{1}\right) \frac{\mathrm{d} \Omega}{\mathrm{dt}}+\mathrm{C}_{3} \Omega+\mathrm{C}_{4}
$$

Replacing $\mathrm{u}$ in (23), we find:

$$
\frac{\mathrm{dS}}{\mathrm{dt}}=-\frac{\mathrm{K} \cdot \mathrm{sat}(\mathrm{S})}{\mathrm{C}_{1}}
$$

Which means that the Lyapunov stability condition is checked.

In the ideal case, the system presents no parametric uncertainties:

$$
\mathrm{S}=0 \quad \Rightarrow \quad \frac{\mathrm{dS}}{\mathrm{dt}}=0
$$

Int J Pow Elec \& Dri Syst, Vol. 10, No. 3, Sep 2019 : 1167 - 1177 
If the system has parametric uncertainties, (23) becomes:

$$
\frac{\mathrm{d} S}{\mathrm{dt}}=\mathrm{g}\left(\Omega, \frac{\mathrm{d} \Omega}{\mathrm{dt}}\right)+\Delta \mathrm{g}-\frac{\mathrm{U}}{\mathrm{C}_{1}}
$$

With $\Delta \mathrm{g}$ is the term representing parametric uncertainties.

Which means that at $\mathrm{S}=0$ :

$$
\frac{\mathrm{dS}}{\mathrm{dt}}=\Delta \mathrm{g} \neq 0
$$

So the state trajectory ends up leaving the sliding surface. And a static error appears therefore.

\subsection{Fuzzy logic controller}

Today, fuzzy regulation is a major branch of regulation technology. The fuzzy controller has achieved the greatest success in industrial and commercial applications of fuzzy methods. Fuzzy controllers are nonlinear regulators. Three phases of treatment take place in a fuzzy regulator Figure 4, Fuzzification, Inference and Defuzzification [10].

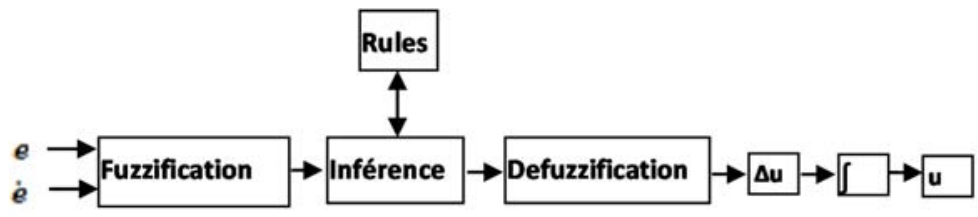

Figure 4. Fuzzy logic controller

\subsection{Fuzzy logic controller implementation}

At the beginning we proceeded to a normalization of the input-outputs, ie the inputs and output of the fuzzy controller are all transformed to a value between -1 and 1 ; for that, we divided on the maximum values that the error and its time derivative can take. The output also takes values between -1 and 1 , before being multiplied by a gain that will be integrated to give the duty cycle value that attacks the engine.

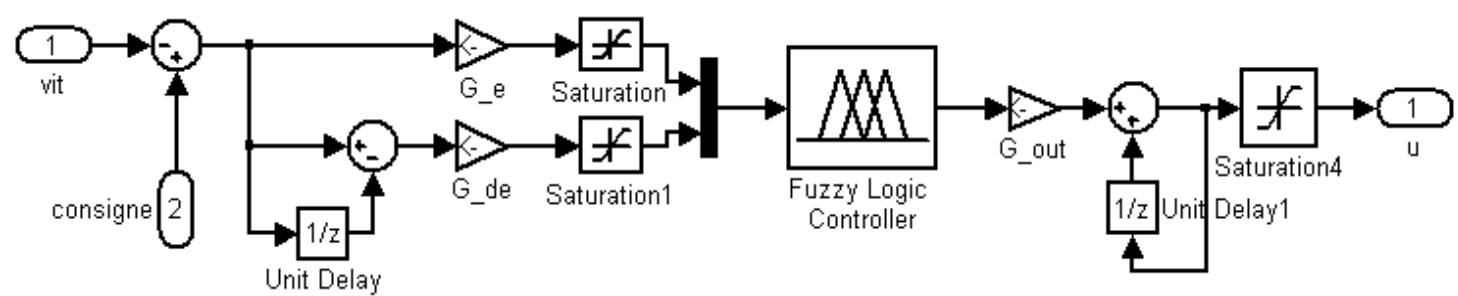

Figure 5. Scheme of the fuzzy logic controller in simulink environnement

G_e $=3,33.10^{-4}$ :input error gain, to make it between -1 and1we divided it on the maximum the speed value.

$\mathrm{G}_{-}{ }_{\mathrm{de}}=3 \cdot 10^{-2}$ :derivative gain of the error, here we have used just the difference $(\mathrm{e}(\mathrm{k})-\mathrm{e}(\mathrm{k}-1))$ the step calculation time is constant and equal to $10^{-4} \mathrm{~s}, 33$ is the maximum value of this difference found from an open-loop test.

G_out $=2,5.10^{-2}:$ with a calculation step of $0.1 \mathrm{~ms}$

\section{THE PROPOSED METHOD}

Sliding mode control has the advantage of being able to drive the system in finite time, but the chattering problem which can only be reduced to detriment of static precision limits its performance. So, to

Real-time implementation of a novel hybrid fuzzy sliding mode control of a BLDC motor (Ali Mousmi) 
benefit from its quick response, we propose in this paper to combine two laws of control, the sliding mode in the transient regime and a fuzzy controller that will take over as much as we approach the static regime.So, we can enjoy the complementary performance of these two controllers' types, by providing a quick reaction against disturbances and changes of instructions, moreover the command accuracy will be provided by fuzzy controller. The idea is to reduce the error of the speed up to a satisfactory value by relying mainly on the SMC organ, and then start to relay gradually to the Fuzzy controller.

The combination of these two controllers will be provided by a simple function (34), which allows to select or give the advantage to the most favorable command depending on the error.

\subsection{Setting up the command and stability discussion}

We have :

$\frac{\mathrm{dS}}{\mathrm{dt}}==-\frac{\mathrm{u}}{\mathrm{C}_{1}}+\mathrm{g}\left(\Omega, \frac{\mathrm{d} \Omega}{\mathrm{dt}}\right)$

Applying the following command

$$
\mathrm{u}=(1-\alpha) \mathrm{K} \cdot \operatorname{sign}(\mathrm{S})+\alpha \mathrm{u}_{\text {Fuzzy }}
$$

With $\alpha$ is the selection parameter calculated based on the errore.

In this work, we calculate it using the following function:

$$
\alpha=\frac{1}{1+\gamma \cdot|\mathrm{e}|}
$$

e is the speed error. $\gamma$ is a positive constant which allows setting of the speed error. $\mathrm{e}_{\text {seuil }}$ is the value from wich $\alpha$ becomes less than 0.1 .

First we fix the parameter $\gamma$ by choosing a threshold of $\mathrm{e}_{\text {seuilsuch }}$ us :

$$
\left\{\begin{array}{l}
\mathrm{e}>\mathrm{e}_{\text {seuil }} \Rightarrow \alpha<0.1 \\
\alpha=0.1=\frac{1}{1+\gamma \cdot\left|\mathrm{e}_{\text {seuil }}\right|} \Rightarrow \gamma=\frac{9}{\mathrm{e}_{\text {seuil }}}
\end{array}\right.
$$

It means that as long as $\mathrm{e}>\mathrm{e}_{\text {seuil }}$ the command takes more than $90 \%$ from the SMC and $10 \%$ from the SMC. Replacings (33) in (32):

$$
\frac{\mathrm{dS}}{\mathrm{dt}}=-\frac{1}{\mathrm{C}_{1}}(1-\alpha) \mathrm{K} \cdot \operatorname{sign}(\mathrm{S})-\frac{1}{\mathrm{C}_{1}} \alpha \mathrm{u}_{\mathrm{Fuzzy}}+\mathrm{g}\left(\Omega, \frac{\mathrm{d} \Omega}{\mathrm{dt}}\right)
$$

According to the convergence condition (25), if the condition (35) is satisfied, the state trajectory convergence towards $\mathrm{S}=0$ is ensured:

$$
(1-\alpha) \mathrm{K}>-\alpha \mathrm{u}_{\text {Fuzzy }}+\mathrm{C}_{1} \cdot \mathrm{g}\left(\Omega, \frac{\mathrm{d} \Omega}{\mathrm{dt}}\right)
$$

According to the selection function $\alpha$ taking into account the condition in (37), if : $\alpha<0.1$ we have:

$$
0.9>(1-\alpha) \mathrm{K}>-\alpha \mathrm{u}_{\mathrm{Fuzzy}}+\mathrm{C}_{1} \cdot \mathrm{g}\left(\Omega, \frac{\mathrm{d} \Omega}{\mathrm{dt}}\right)
$$

So, if :

$$
\mathrm{K}>\frac{\mathrm{C}_{1}}{9} \mathrm{u}_{\text {Fuzzy }}+\frac{\mathrm{C}_{1}}{0.9} \cdot \mathrm{g}\left(\Omega, \frac{\mathrm{d} \Omega}{\mathrm{dt}}\right)
$$

We guarantee the inclusion of the state trajectory in a domain where:

$$
|\mathrm{e}|<\mathrm{e}_{\text {seuil }}
$$

In this paper, $\mathrm{K}$ is equal to 1.2 .

Int J Pow Elec \& Dri Syst, Vol. 10, No. 3, Sep 2019 : 1167 - 1177 


\section{EXPERIMENT RESULTS}

In all experiences aBLDC motor with axial flux is used, $3 \mathrm{KW}, 80 \mathrm{~V}, 8$ poles (Figure 6), an inverter which can operate at $12 \mathrm{kHz}$ maximal switching frequency based on IGBTs, a dsPace card DS1104 operating at $20 \mathrm{MHz}$ and a PC with Control Disk interface for data acquisition.

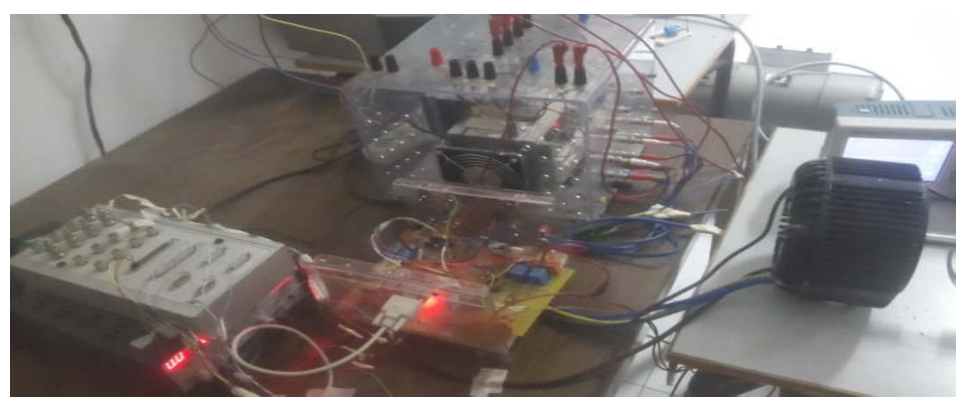

Figure 6. Experimental platform of system

To evaluate the proposed controller performances, one compared its behavior with the fuzzy controller applied alone. (Figure 7), (Figure 8) and (Figure 9)present respectively the speed response of the proposed, the fuzzy logic and conventional sliding mode controllers following a speed reference of 1500 $\mathrm{rpm}$, the motor at the beginning is at rest. (Figure 10), (Figure 11), (Figure 12) and (Figure 13) respectively give: the response of the proposed controller to variable reference from 0,1500 then $2500 \mathrm{rpm}$, the evolution of the selection function, the command output and the outputs of both controller FLC and SMC. (Figure 14) and (Figure 15) visualize a comparison between the proposed controller and fuzzy controller behaviors against a disturbance of $15 \mathrm{~V}$ at the power source, the behavior of the selection function and the output of the proposed regulator are given in (Figure 16) and (Figure 17).

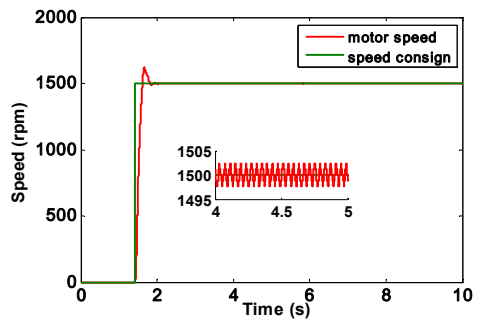

Figure 7. Speed response of the proposed controller

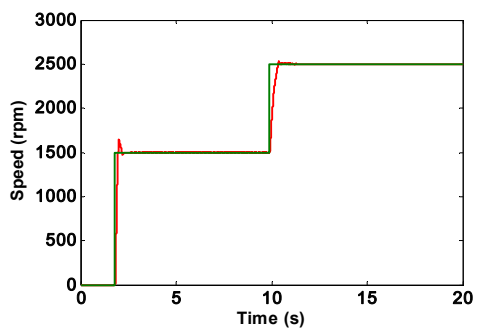

Figure 10. Speed response to a variable consign

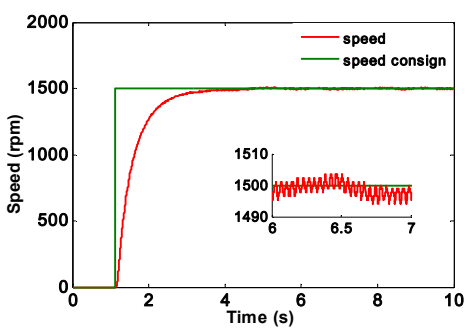

Figure 8. Speed response of th FLC

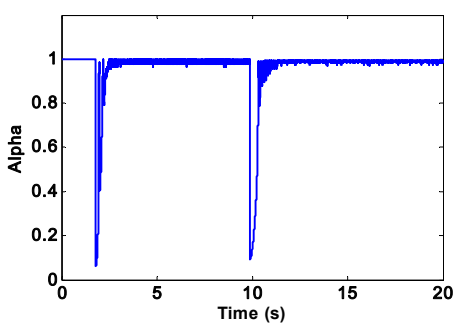

Figure 11. Selection function

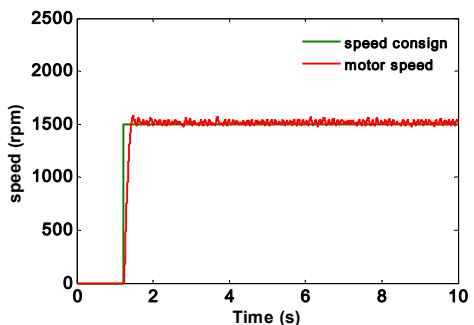

Figure 9. Speed response of th $\mathrm{SMC}$

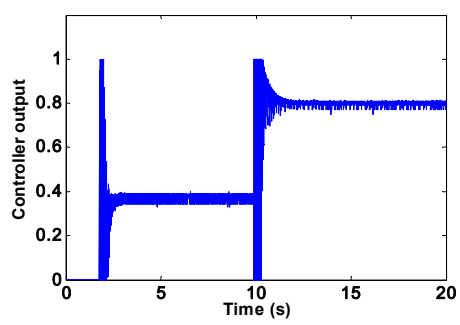

Figure 12. Commande output 


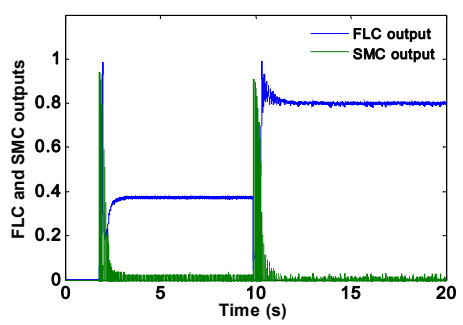

Figure 13. SMC and FLC controllers outpts

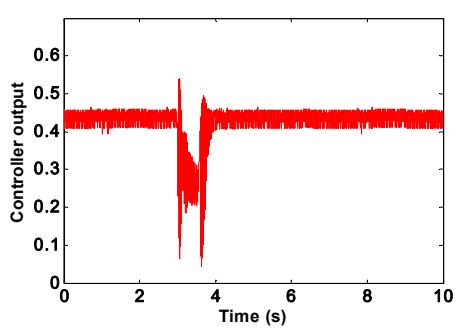

Figure 16. Commande output

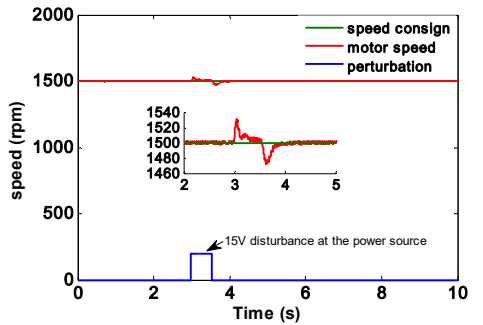

Figure 14. Reaction of the proposed controller against a disturbance

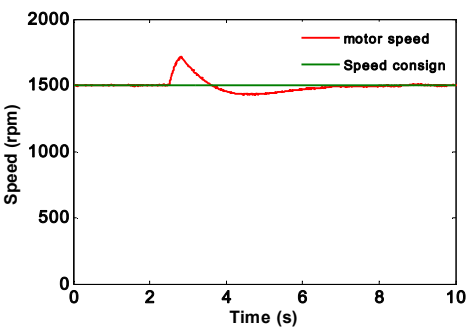

Figure 17. The FLC Reaction against a disturbance

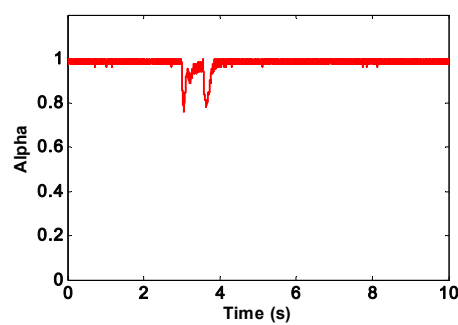

Figure 15. Selection function

\section{CONCLUSION}

This paper proposes a new hybrid controller based on fuzzy logic and sliding mode theories. The aim is to set up a controller that can exploit the fastresponse of Brushless motors. The new controller is designed in a way to combine the complementary advantages of these two command laws and removing their disadvantages.After the new controller's presentation and its stability discussion, one used it to control a Brushless DC motor, then discussed and compared its performance with those of fuzzy logic and sliding mode controllers. The experimental results show the superiority of the proposed controller in terms of response speed, reaction against disturbances and static accuracy.

\section{ACKNOWLEDGEMENTS}

The authors would like to acknowledge the financial support of the national center for scientific and technical research in Morocco (CNRST).

\section{REFERENCES}

[1] T. Shi, Y. Guo, P. Song, and C. Xia, "A new approach of minimizing commutation torque ripple for blushless dc motor based on dc-dc converter," IEEE Trans. Ind. Electron., vol. 57, no. 10, pp. 3483-3490, Oct. 2010.

[2] Z. Q. Zhu and D. Howe, "Electrical machines and drives for electric, hybrid, and fuel cell vehicles," Proc. IEEE, vol. 95 , no. 4, pp. 746765 , Apr. 2007.

[3] Ali. Mousmi, Ahmed. Abbou and Yassine El Houm, 'Trapezoidal control of brushless DC motor based on DSP F28335', IEEE International Conference onWireless Technologies, Embedded and Intelligent Systems (WITS), morocco2017. DOI: 10.1109/WITS.2017.7934602.

[4] M. A. Shamseldin, and A. M. A. Ghany, M. A. A. Ghany, "Performance Study of Enhanced Non-Linear PID Control Applied on Brushless DC Motor," International Journal of Power Electronics and Drive System (IJPEDS), vol. 9, no.2, pp. 536-545, 2018

[5] H. S. Choi, Y. H. Park, Y. S. Cho, and M. Lee, "Global sliding-mode control improved design for a brushless DC motor," IEEE Control Systems Magazine, vol. 21, pp. 27-35, 2001.

[6] L. P. Guo, J. Y. Hung, R. M. Nelmsb, "Comparative evaluation of sliding mode fuzzy controller and PID controller for a boost converter", Electric Power Systems Research, vol. 81, no.1, pp. 99-106, Jan. 2011.

[7] M.A Fnaeich. F.Betin. G-A. Capolino, and F. Fnaeich, "Fuzzy logic and sliding-mode controls appleid to sex-phase induction machine with open phases," IEEE Trans. Ind Electron., vol. 57, no. 1, pp. 354-364, Jan. 2010 
[8] Akram H. Ahmed, Abd El Samie B. Kotb, Ayman M.Ali, "Comparaison between fuzzy logic and PI control for the speed of bldc motor", International Journal of Power Electronics and Drive System (IJPEDS), vol. 9, no. 3, pp. $1116-1123,2018$.

[9] Liu Y.,Zhao J.,Xia M.,and Luo H., "Model reference adaptive controlbased speed control of brushless DC motors with low-resolution hall- 1443 effect sensors," IEEE Transactions on Power Electronics,vol.29, no. 3,pp. 15141522,March 2014

[10] Mohamed Benbouzid, Brice Beltran, Yassine Amirat, Gang Yao, Jingang Han and Hervé Mangel, "Higher-order Sliding Mode Control for DFIG-Based Wind Turbine Fault Ride-Through" Industrial Electronics Society, IECON 2013 - 39th Annual Conference of the IEEE. DOI:10.1109/IECON.2013.6700411,2013.

[11] V. Utkin. "Sliding Modes in Control Optimization,". Springer, Berlin, 1992.

[12] Itksis, U. "Control systems of Variable Structure", Wiley, New York, 1976, 400p.

[13] V. Utkin, J. Guldner, and S. Jingxin. "Sliding Mode Control in Electromechanical Systems," Systems and Control. Taylor \& Francis, London, 1999.

[14] Levant A.and Alelishvili L., "Integral high-order sliding modes," IEEE Trans. Automatic Control, vol. 52, n 7, pp. 1278-1282, July 2007.

[15] Beltran B., Benbouzid M.E.H. and Ahmed-Ali T., "Second-order sliding mode control of a doubly-fed induction generator driven wind turbine," IEEE Transactions on Energy Conversion, DOI: 10.1109/TEC.2011.2181515, 2012.

[16] Mohamed Benbouzid, Brice Beltran, Yassine Amirat, Gang Yao, Jingang Han and Hervé Mangel, "Higher-order Sliding Mode Control for DFIG-Based Wind Turbine Fault Ride-Through," Industrial Electronics Society, IECON 2013 - 39th Annual Conference of the IEEE. DOI:10.1109/IECON.2013.6700411,2013

[17] Shahsadeghi, M., Khooban, M.H., Niknam, T.: "A robust and simple optimal type II fuzzy sliding mode control strategy for a class of nonlinear chaotic systems”, J. Intell. Fuzzy Syst., Appl. Eng. Technol., 2014, 27, (4), pp. 1849 1859

[18] Soltanpour, M.R., Otadolajam, P., Khooban, M.H.: "Robust control strategy for electrically driven robot manipulators: adaptive fuzzy sliding mode", IET Sci. Meas. Technol., 2014, 9, (3), pp. 322-334

[19] Wong, L.-K., Leung, F.H-F., Tam, P.K-S.: "A fuzzy sliding controller for nonlinear systems", IEEE Trans. Ind. Electron., 2001, 48, pp. 32-37

[20] R. Cepeda-Gomez, N. Olgac, D.A. Sierra, "Application of sliding mode control to swarms under conflict", IET Control theory and applications, vol. 5, pp, 1167-1175 2011.

[21] L. A. Zadeh, "Fuzzy Sets," Information and control, Vol. 8, 1965, pp. 338-353. 